\title{
Prognostic and Predictive Role of Neutrophil to lymphocyte Ratio in Second Line Immunotherapy of Non-small Cell Lung Cancer
}

\author{
Chiara Bennati ${ }^{1,}$, , Manolo D’Arcangelo ${ }^{1}$, Alessio Gili ${ }^{2}$, Federica Gazzaneo ${ }^{1}$, Sara Pini ${ }^{1}$, \\ Antonello Menghi ${ }^{1}$, Marco Montanari ${ }^{1}$, Giorgio Papiani ${ }^{1}$, Valentina Mazza ${ }^{1}$, Simona Scodes ${ }^{1}$, \\ Michela Spreafico $^{3}$, Giulio Rossi ${ }^{4}$, Dora Caruso ${ }^{4}$, Guido Bellezza ${ }^{5}$, Martina Mandarano ${ }^{5}$, \\ Stefano Tamberi ${ }^{1}$ \\ ${ }^{1}$ Department of Oncology-Hematology, AUSL della Romagna, Santa Maria delle Croci Hospital, Ravenna, Italy \\ ${ }^{2}$ Department of Medicine and Surgery, University of Perugia, Perugia, Italy \\ ${ }^{3}$ Unit of Biostatistics and Clinical Trials, Istituto Scientifico Romagnolo per lo Studio e la Cura dei Tumori (IRST), IRCCS, Meldola (FC), Italy \\ ${ }^{4}$ Operative Unit of Pathology, AUSL della Romagna, Santa Maria delle Croci Hospital, Ravenna, Italy \\ ${ }^{5}$ Department of Medicine and Surgery, Section of Anatomic Pathology and Histology, University of Perugia, Perugia, Italy
}

Email address:

chiarabennati@libero it (C. Bennati)

${ }^{*}$ Corresponding author

\section{To cite this article:}

Chiara Bennati, Manolo D’Arcangelo, Alessio Gili, Federica Gazzaneo, Sara Pini, Antonello Menghi, Marco Montanari, Giorgio Papiani, Valentina Mazza, Simona Scodes, Michela Spreafico, Giulio Rossi, Dora Caruso, Guido Bellezza, Martina Mandarano, Stefano Tamberi. Prognostic and Predictive Role of Neutrophil to lymphocyte Ratio in Second Line Immunotherapy of Non-small Cell Lung Cancer. International Journal of Clinical Oncology and Cancer Research. Vol. 6, No. 2, 2021, pp. 98-108. doi: 10.11648/j.ijcocr.20210602.16

Received: May 11, 2021; Accepted: May 27, 2021; Published: June 28, 2021

\begin{abstract}
Background: Programmed death-ligand 1 (PD-L1) expression at immunohistochemistry is the only approved, but still unsatisfactory, biomarker for immunotherapy in Non-Small Cell Lung Cancer (NSCLC). Neutrophil to Lymphocyte ratio (NLR) is a surrogate of systemic inflammation and could correlate with outcome to immunotherapy. This retrospective study (NCT03816657) explored the role of NLR in predicting benefit to nivolumab and susceptibility to hyperprogression (HPD). Methods: PD-L1, baseline and on-therapy NLR values were available in 173 NSCLC patients receiving nivolumab. PD-L1 positivity was defined as expression on $\geq 1 \%$ of tumor cells; NLR was dichotomized in high $(\geq 5)$ or low $(<5)$. Patients were divided in 4 cohorts: 1 (PD-L1+/low NLR), 2 (PD-L1-/high NLR), 3 (PD-L1+/high NLR), 4 (PD-L1-/low NLR). A landmark analysis explored the impact of cohorts and NLR change on objective response rate (ORR), progression-free survival (PFS), overall survival (OS) and its influence on HPD. Results: PD-L1 was positive in $48 \%$ and negative in $52 \%$ of cases. Pre-treatment NLR was $\geq 5$ in $42 \%$ and $<5$ in $58 \%$ of patients; on-treatment NLR was $\geq 5$ in approximately $50 \%$ of patients. PD-L1 positivity was not associated with outcome. Both high pre- and on-therapy NLR was a negative predictor of ORR $(p=0.004)$, PFS $(p<0.0001)$ and OS $(p<0.0001)$. High NLR cohorts $(2$ and 4$)$ showed poorer outcome than low NLR cohorts. Relative NLR excursion $\geq 25 \%$ at 4 weeks from nivolumab start was associated with reduced PFS and OS, while its decrease or stability was associated with improved outcomes. Although NLR value and its dynamic did not influence HPD occurrence $(\mathrm{p}=0.062), 53 \%$ of hyperprogressors belonged to high NLR cohorts. Conclusion: The current retrospective analysis supports the role of high NLR as a independent negative predictive factor. Its increment during immunotherapy may identify patients with low likelihood of response to immunotherapy.
\end{abstract}

Keywords: Non-small Cell Lung Cancer, Programmed Death Ligand 1, Neutrophil to Lymphocyte Ratio, Nivolumab, Hyperprogression 


\section{Introduction}

Over the last 5 years, treatment of advanced non-small cell lung cancer (NSCLC) with unknown driver mutations has been revolutionized by the approval of checkpoint inhibitors as single agents or in combination with chemotherapy in the first-line setting [1-5]. Although these advances we are still facing the challenge of the lack of reliable predictive biomarkers of mono-immunotherapy in the second-line scenario. Despite unanimous evidence of a trend toward improved outcome in patients with high expression of PD-L1, its role in predicting benefit is still controversial [6-9]. Recent retrospective analyses suggested a potential role of immunotherapy re-challenge leading to survival advantage, butalso in this subset of patients PD-L1 has poor predictive value [10, 11]. Among investigated biomarkers, tumor mutational burden (TMB) was the most promising but failed to predict a homogeneous survival benefit across different trials. At the moment, evidence of an association between PD-L1 expression and TMB is inconsistent [12, 13]. Another aspect of mono-immunotherapy is the controversial phenomenon of hyperprogression (HPD), a tremendous acceleration of disease growth observed in up to $30 \%$ of immunotherapy patients $[14,15]$. Biological mechanisms are currently only theoretic and the prediction of susceptibility to HPD still remains elusive [16-18]. Recent studies show that pre-treatment Neutrophil to Lymphocyte ratio (NLR, quotient of absolute neutrophil and lymphocyte count) is a prognostic marker for several tumors and predictive of outcome to immunotherapy [19-21]. Although the best cut-off value has not been established, it is widely accepted that a NLR of 5 discriminates populations with different prognosis, in particular a NLR $\geq 5$ is associated with the worst outcome [22-26]. Lately, attention has been focused on NLR excursion during treatment: high post-treatment values were significantly associated with poor survival in advanced cancers [27, 28].

Based on the evidence that the application of immunotherapy cannot be determined only by one predictive factor, we hypothesized that the integration of PD-L1 status and NLR could discriminate cohorts of patients with different benefit to treatment. We also explored the role of on-therapy NLR and of its evolution in influencing outcomes during immunotherapy. In order to define the difference between nivolumab and chemotherapy-induced HPD, we evaluated the incidence of this unraveling phenomenon in the frontline setting with cisplatin-based chemotherapy versus any line immunotherapy.

\section{Materials and Methods}

\subsection{Patients}

The population of this retrospective analysis (NCT03816657) included consecutive patients with advanced NSCLC who received at least one cycle of second or later line nivolumab $(3 \mathrm{mg} / \mathrm{kg}$ intravenously every 2 weeks) in two Italian Institutions (Hospital of Ravenna and Hospital of Perugia) between February 2015 and June 2019.

The study was approved by the local Ethical Committee (Comitato Etico della Romagna, CEROM). Patient data and laboratory results were recorded in an electronic anonymized database. Patients with squamous-cell cancers were considered as wild-type for targetable mutation, considered the low frequency of known druggable mutations in this population.

\subsection{PD-L1 and NLR Assessment}

PD-L1 expression was assessed on available archival tissue samples by immunohistochemistry (IHC) with clone 22C3 (monoclonal rabbit; Agilent Technologies, Santa Clara, CA) in a Ventana automated immunostainer (ULTRA, Ventana Medical Systems) according to the manufacturer's protocol and using proprietary reagents. We quoted PD-L1 positivity as expression on $\geq 1 \%$ of tumor cells. NLR value was obtained dividing the absolute neutrophil count by the lymphocyte value measured in peripheral blood at two time points: pre-treatment (within 4 weeks prior to the first infusion of nivolumab: median time 2 weeks); on-treatment (within 4 weeks after the first nivolumab infusion: median time 26 days). Based on historical evidences that a NLR ratio higher than 5 is associated with poor outcome [22-26], patients were dichotomized according to a pre-specified cut-off value of NLR as high $(\geq 5)$ or low $(<5)$.

\subsection{Patients Cohorts}

Patients were grouped in four cohorts according to the combined PD-L1/NLR parameters: cohort 1 included PD-L1 negative and low NLR patients $(\mathrm{N}=53)$; cohort 2 included PD-L1 negative and high NLR $(\mathrm{N}=37)$; cohort 3 PD-L1 positive and low NLR $(\mathrm{N}=47)$ and cohort 4 PD-L1 positive and high NLR $(\mathrm{N}=36)$. In order to identify subgroups of patients with different sensibility to nivolumab a comparison of outcomes between the four cohorts was carried out.

\subsection{Endpoints}

The primary end point was overall response rate ORR calculated as the percentage of complete (CR) and partial responses (PR) among all treated patients. Response to treatment was assessed by computed tomography and classified according to RECIST 1.1 criteria [29]. Secondary outcome were overall survival (OS) and progression free survival (PFS), calculated from the start of nivolumab treatment to death and radiographic progression, respectively.

To evaluate the risk of HPD with nivolumab compared to chemotherapy, response to first line platinum doublet was collected for the same group of patients. 


\section{Statistical Analysis}

Descriptive statistics was performed using frequencies, percentages, frequency tables for categorical variables, median and means \pm standard deviation $(S D)$ for quantitative variables. Categorical variables were evaluated by Chi-square or Fisher's exact test depending on the number of patients per group. The influence of the combined PD-L1/NLR parameters on ORR was analyzed by logistic regression approach.

Multivariate Cox proportional hazards models were used to determine whether PD-L1, NLR, combined PD-L1/NLR and other baseline characteristics were associated with PFS and OS. The Kaplan-Meier method was used to analyze survival and estimate medians with two-sided $95 \%$ confidence intervals (CI). Survival curves were compared using the log-rank test. Candidate prognostic factors with a 0.2 significance level in univariate analysis were entered in a multivariate Cox model and a backward-selection procedure was used to determine independent prognostic factor. A p-value of less than 0.05 was consider to be statistically significant. Statistical analyses were performed with STATA v. 16.1 (Stata Corp LP, College Station, TX, USA).

Table 1. Patients' and tumor characteristics.

\begin{tabular}{|c|c|}
\hline Patients' and Tumor characteristics $(n=173)$ & n (\%) \\
\hline \multicolumn{2}{|l|}{ Age (years) } \\
\hline Median & 65 \\
\hline Range & $30-84$ \\
\hline$>70$ & $61(35)$ \\
\hline \multicolumn{2}{|l|}{ Sex } \\
\hline Male & $114(66)$ \\
\hline Female & $59(34)$ \\
\hline \multicolumn{2}{|l|}{ ECOG PS } \\
\hline 0 & $85(49)$ \\
\hline 1 & $75(43)$ \\
\hline 2 & $12(7)$ \\
\hline 3 & $1(1)$ \\
\hline \multicolumn{2}{|l|}{ Smoking history } \\
\hline Never & $24(14)$ \\
\hline Current Smokers & $116(67)$ \\
\hline \multicolumn{2}{|l|}{ Histology } \\
\hline Squamous & $47(27)$ \\
\hline Non-squamous & $126(73)$ \\
\hline \multicolumn{2}{|l|}{ Mutational Status } \\
\hline EGFR & $8(9)$ \\
\hline K-RAS & $45(29)$ \\
\hline ALK & $1(1)$ \\
\hline Others (BRAF, HER2, MET, ROS1) & $3(3)$ \\
\hline \multicolumn{2}{|l|}{ Therapy Line with Nivolumab } \\
\hline 1 & $5(3)$ \\
\hline 2 & $105(61)$ \\
\hline$\geq 3$ & $63(36)$ \\
\hline \multicolumn{2}{|l|}{ Site of metastases at diagnosis } \\
\hline Lung/Pleura & $91(53)$ \\
\hline Brain & $26(15)$ \\
\hline Nodes & $37(21)$ \\
\hline Others & $29(17)$ \\
\hline \multicolumn{2}{|l|}{ Sites of progression on Nivolumab } \\
\hline Lung/Pleura & $91(52)$ \\
\hline Brain & $36(21)$ \\
\hline Bone & $47(27)$ \\
\hline Liver & $30(17)$ \\
\hline Nodes & $12(7)$ \\
\hline Others & $8(4)$ \\
\hline \multicolumn{2}{|l|}{ Pre-treatment NLR } \\
\hline$\geq 5$ & $73(42)$ \\
\hline$<5$ & $100(58)$ \\
\hline \multicolumn{2}{|l|}{ On-treatment NLR } \\
\hline$\geq 5$ & $86(49)$ \\
\hline$<5$ & $87(51)$ \\
\hline \multicolumn{2}{|l|}{ PD-L1 status } \\
\hline$\geq 1 \%$ & $83(48)$ \\
\hline$<1 \%$ & $90(52)$ \\
\hline
\end{tabular}




\section{Results}

\subsection{Patients and Tumor Characteristics}

A total of 173 patients were treated with a median of 8 cycles (range 1-37) of nivolumab. Median duration of follow-up was 7.5 months (95\% CI: 0.3-94.6). Analysis of EGFR/KRAS/BRAF/HER2/MET mutations and ALK/ROS1 rearrangements were performed in all advanced adenocarcinomas. Patients and tumor characteristics are summarized in Table 1.
Median baseline and on-treatment NLR value was 4 (range, 0.5-7) and 4.9 (range, 0.9-34), respectively. Pre-treatment NLR was $\geq 5$ in 73 patients $(42 \%$, , on-treatment NLR was $\geq 5$ in approximately $50 \%$ of patients. PD-L1 was positive $(\geq 1 \%)$ in 83 cases $(48 \%)$. Based on such characteristics, 53 patients (31\%) were included in cohort 1 (PD-L1-/low NLR), 37 (21\%) in cohort 2 (PD-L1-/high NLR), $47(27 \%)$ in cohort 3 (PD-L1+/low NLR) and $36(21 \%)$ in cohort 4 (PD-L1+/high NLR) (Figure 1).

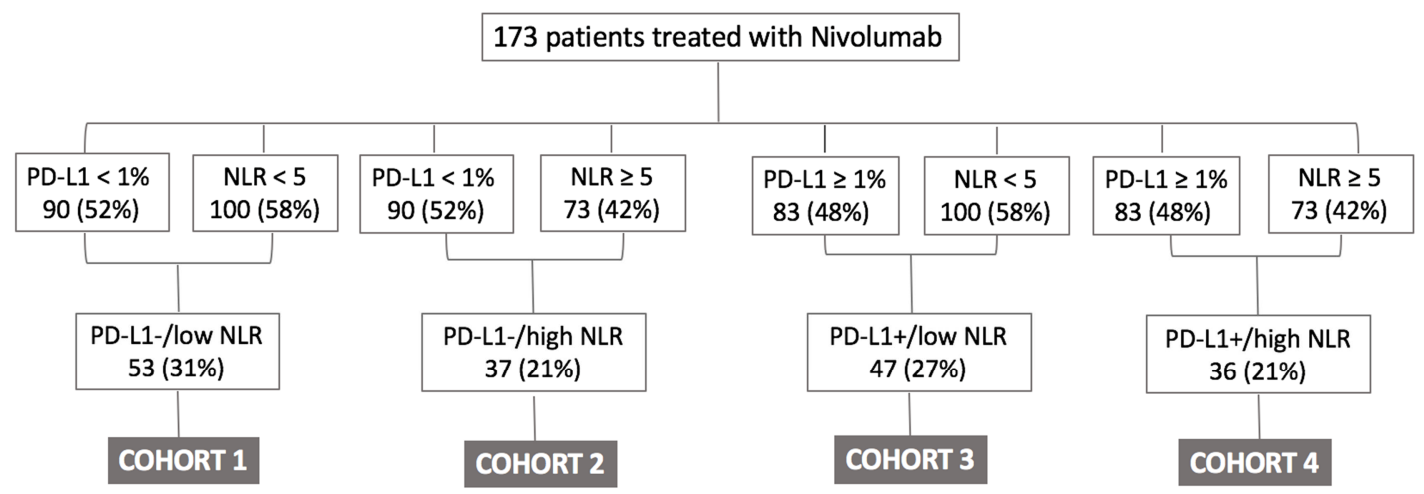

Figure 1. Cohorts Distribution. NLR: Neutrophil to Lymphocyte ratio; PD-L1: Programmed Death Ligand 1.

\subsection{Response}

ORR was $18 \%$ (31 patients; $17 \%$ and $21 \%$ in non-squamous and squamous histology, respectively), including 21 patients with ongoing responses at the time of data collection. Disease control rate (DCR, consisting of CR, PR, and stable disease SD) was $51 \%$ (51 of 88 patients). Responses were durable (median 8.4 months, range 0.23-72.08) (Table 2). Among the 8 patients with EGFR mutation, $1(12.5 \%)$ had a partial response. The ALK positive patient reached a 4-months

stability of disease as best response. Among the 44 patients with KRAS mutation, 5 (16\%) obtained a partial response.
While response was not affected by PD-L1 status, both high baseline and on-therapy NLR significantly predicted poorer outcome: ORR in pre-treatment NLR $<5$ was $25 \%$ [95\% CI 17.4-34.5] vs $8.2 \%$ in NLR $\geq 5$ [95\% CI 3.6-17.3], $\mathrm{p}=0.004$. Considering the on-treatment value of NLR, ORR was $26.4 \%$ [95\% CI 18.1-36.8] in NLR < 5 vs 9.3\% [CI 4.6-17.6] in NLR $\geq 5, \mathrm{p}=0.003$. In addition, low response rate to nivolumab was observed in high NLR cohorts 2 and 4 compared to low NLR cohorts 1 and 3: cohort 1 ORR 24.5\% (95\% CI14.6-38.1); cohort 2 ORR $10.8 \%$ (95\% CI 3.9-26.1); cohort 3 ORR $25.5 \%$ (95\% CI 14.8-40.2); cohort 4 ORR 5.5\% (95\% CI 1.3-20.4).
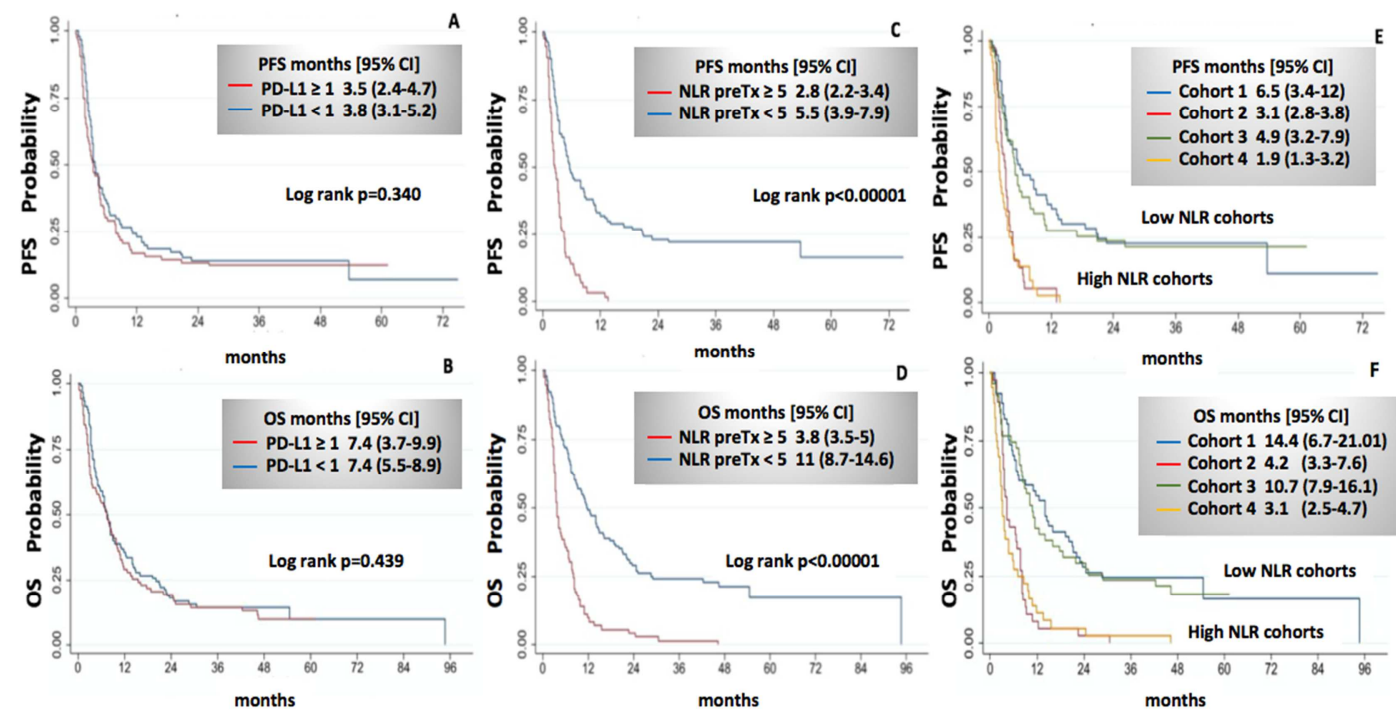

Figure 2. PFS (A) and OS (B) probability in PD-L1<1\% or $\geq 1 \%$. PD-L1 positivity was not associated with outcomes; PFS (C) and OS (D) probability in baseline NLR $<5$ or $\geq 5 . N L R N \geq 5$ independently correlates with worse PFS and OS. PFS (E) and OS (F) probability in cohorts 1-4. High NLR cohorts significantly correlate with poorer PFS and OS. 


\subsection{Survival}

Median PFS was 3.5 months (95\% CI 3.1-4.5months). PD-L1 positivity was not associated with PFS $(\mathrm{p}=0.340)$ and OS $(p=0.439)$, while high baseline and on-treatment NLR strongly correlated with shorter PFS $(p<0.0001$ and $p=0.015$ respectively) and $\mathrm{OS}(\mathrm{p}<0.0001$ and $\mathrm{p}=0.001$, respectively) (Figure 2). In the Cox regression analysis for PFS and OS the variables included were: age, sex, ECOG PS, smoking history, histology, brain/bone/liver involvement at diagnosis, mutational status, PD-L1 expression, baseline and on-therapy NLR level, and cohorts. Bone metastases at baseline (HR 1.43 [1.01-2.02], $\mathrm{p}=0.038)$, high pre- and on-treatment NLR (HR 2.97 [2.10-4.21], $\mathrm{p}<0.00001$ and HR 2.3 [1.6-3.2], $\mathrm{p}<0.00001$, respectively) and belonging to cohorts 2 and 4 (HR 2.8 [1.76-4.52], $\mathrm{p}<0.00001$ and HR 3.46 [2.18-5.51], $\mathrm{p}<0.00001$, respectively) significantly predicted poorer PFS. In the multivariate analysis high NLR confirmed the strong influence on PFS, irrespective of the timing of sampling (pre-therapy NLR: HR $2.30 \quad[1.55-3.40], \quad \mathrm{p}<0.0001$; on-therapy NLR: HR 1.59 [1.09-2.33], p 0.015).

In this heavily pretreated population median OS was 7.4 months [95\% CI 5.8-8.5] with 1-year OS rate of $32 \%$ [95\% CI 25-39]. At the univariate analysis bone metastasis at diagnosis (HR 1.41 [1-1.99], $\mathrm{p}=0.048$ ) and high pretreatment and on-treatment NLR (HR 3.04 [2.16-4.26], p $<0.00001$ and HR 2.3 [1.8-3.6], $\mathrm{p}<0.00001$, respectively) predicted poorer OS. The multivariate analysis confirmed the detrimental influence of both high pre- (HR 2.30 [1.55-3.39], $\mathrm{p}<0.0001)$ and on-therapy NLR (HR 1.88 [1.28-2.77], p=0.001) on OS (Table 3 ); interestingly, this analysis showed a potential deleterious effect of immunotherapy in males vs females (HR 1.53 [1.07-2.16], $p=0.017)$. Lastly, as confirmed by responses, high NLR cohorts 2 and 4 showed significant worsePFS and OS compared to low NLR cohorts1 and 3, irrespective of PD-L1 value (Figure 2).

\subsection{Impact of NLR Excursion During Immunotherapy}

Once we confirmed the negative predictive role of high NLR on the immunotherapy effectiveness, we hypothesized that its early variation from baseline could predict in advance a variable response to nivolumab, even before radiological detection. A landmark analysis was conducted to explore the effect of NLR change on ORR, PFS and OS. Excursion was defined as an arbitrary $25 \%$ increase or decrease in early NLR on-treatment value according to a 3 groups definition: group A $\geq 25 \%$ increase, group B no change $[<25 \%$ decrease to $<25 \%$ increase], group $C \geq 25 \%$ decrease. Sixty-nine patients were included in group A, 72 patients in group B and 32 patients in group C. Patients in group A had the worst PFS (2.9 months, 95\% CI 2.3-3.5) and OS (4.6 months, 95\% CI 3.4-7.4), $\mathrm{p}<$ 0.0001 . Those in groups B and C showed similar PFS (4.6 months, 95\% CI 2.2-7.7 and 5.2 months, 95\% CI 3.4-7.9, respectively) and OS (8.9 months, 95\% CI 5.5-12.3 and 8.9 months, 95\% CI 6.4-14.1) (Figure 3).

Table 2. Tumor response in patients with advanced NSCLC treated with nivolumab. ORR: Overall Response Rate; DCR: Disease Control Rate; DOR: Duration of response.

\begin{tabular}{|c|c|c|c|c|}
\hline \multirow{2}{*}{ Response } & All Patients & p value & Non-Squamous & Squamous \\
\hline & \multicolumn{2}{|l|}{$\mathrm{n}=\mathbf{1 7 3}$} & $\mathrm{n}=126$ & $\mathrm{n}=47$ \\
\hline ORR, n (\%) [95\% CI] & $31(18)[12.8-24.4]$ & & $21(17)[11-24.2]$ & $10(21)[11.6-35.6]$ \\
\hline DCR, n $(\%)[95 \% \mathrm{CI}]$ & $88(51)[43.4-58.2]$ & & $62(49)$ [40.5-57.9] & $26(55)[40.6-69]$ \\
\hline Ongoing responders, n (\%) & $12(7)$ & & $11(9)$ & $1(2)$ \\
\hline DOR, median (range) months & $23(18.6-24.5)$ & & $34.2(0.23-72.8)$ & $3.19(1.6-57.2)$ \\
\hline ORR PDL $1 \geq 1 \%,(\%)[95 \% \mathrm{CI}]$ & $16.8(10.1-26.6)$ & $\mathrm{P}=0.729$ & $13.1[6.6-24.3]$ & $27.2[12.1-50.3]$ \\
\hline ORR PDL $1<1 \%,(\%)[95 \% \mathrm{CI}]$ & $18.8(12-28.4)$ & (ref.) & $20[11.8-31.7$ & $16[5.8-36.9]$ \\
\hline ORR baseline NLR $\geq 5,(\%)[95 \% \mathrm{CI}]$ & $8.2(3.6-17.3)$ & (ref.) & $8.6(3.2-21.4)$ & $7.4(1.7-26.5)$ \\
\hline ORR on-treatment NLR $<5,(\%)[95 \% \mathrm{CI}]$ & $26.4(18.1-36.8)$ & $\mathrm{P}=0.003$ & $26.1[16.7-38.3]$ & $27.2[12.1-50.3]$ \\
\hline ORR on-treatment NLR $\geq 5,(\%)[95 \% \mathrm{CI}]$ & $9.3(4.6-17.6)$ & (ref.) & $6.5[2.4-16.4]$ & $16.1[5.8-36.9]$ \\
\hline ORR Cohort $1,(\%)[95 \% \mathrm{CI}]$ & $24.5(14.6-38.1)$ & - & - & - \\
\hline ORR Cohort $2,(\%)[95 \% \mathrm{CI}]$ & $10.8(3.9-26.1)$ & - & - & - \\
\hline ORR Cohort $3,(\%)[95 \% \mathrm{CI}]$ & $25.5(14.8-40.2)$ & - & - & - \\
\hline ORR Cohort $4,(\%)[95 \% \mathrm{CI}]$ & $5.5(1.3-20.4)$ & - & - & - \\
\hline
\end{tabular}

\subsection{Hyperprogression}

HPD was defined as $>50 \%$ increase in tumor growth rate compared with pre-immunotherapy volume as best response at the first disease evaluation performed after starting nivolumab. HPD occurred in 40\% [95\% CI 32-48] of patients treated with immunotherapy and $22 \%$ [95\% CI 16-29] of patients receiving an upfront platinum-doublet $(p<0.001)$, reinforcing the idea that checkpoint inhibitors may upregulate immune modulators and the expression of oncogenic pathways differently from chemotherapy [30]. Therefore, we examined the potential influence of patients or clinical characteristics on immunotherapy and chemotherapy-related HPD. With nivolumab we observed a significant correlation of HPD with PD-L1 positivity $(\mathrm{p}=0.014)$, adenocarcinoma histology $(p=0.006)$, different sites of metastatic involvement of disease at baseline (liver, $\mathrm{p}=0.0001$; bone, $\mathrm{p}=0.0001$; brain, $\mathrm{p}=0.001$; nodes, $\mathrm{p}=0.020$ ). Interestingly, $53 \%$ of the hyperprogressors to nivolumab (30/57 patients) belonged to high NLR cohorts $(p=0.062)$ suggesting a potential negative influence of high pre-treatment leukocyte count imbalance on outcome to immunotherapy. In the chemotherapy arm no 
specific predictive factors seem to correlate with this

phenomenon (Table 4).
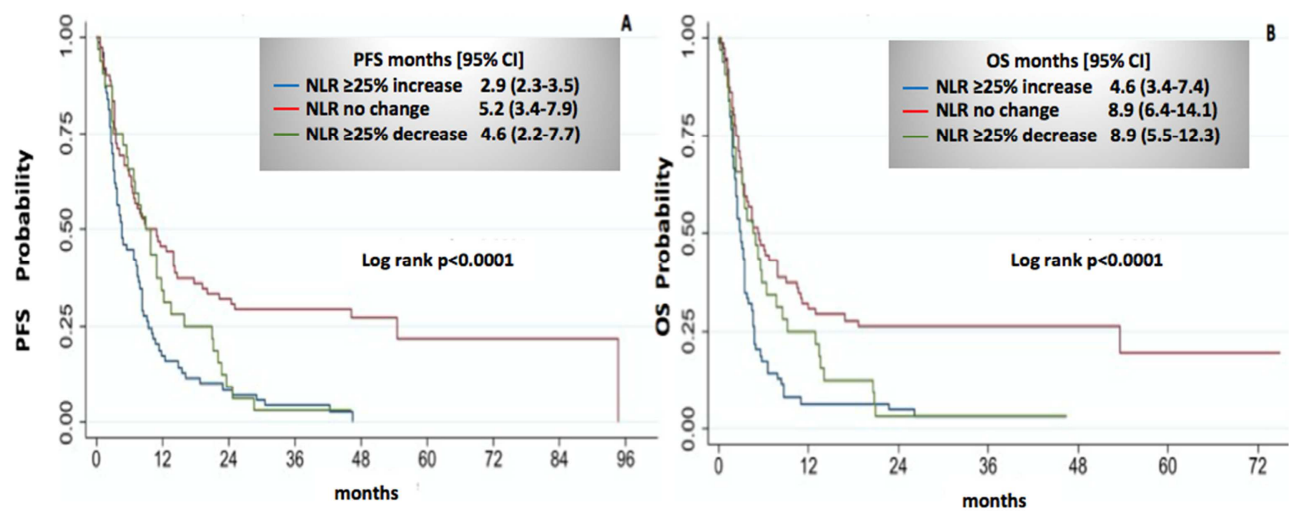

Figure 3. PFS (A) and OS (B) probability in group $1(\geq 25 \%$ NLR increase), group 2 no change $(<25 \%$ NLR decrease to $<25 \%$ NLR increase), group $3(\geq 25 \%$ NLR decrease).

Table 3. Univariate and multivariate analyses progression free survival (PFS). And of overall survival (OS) PFS: Progression Free Survival; OS: Overall Survival; ECOG PS: Eastern Cooperative Oncology Group Performance Status; C/F smokers: current/former smokers; Brain Mets: brain metastases.

\begin{tabular}{|c|c|c|c|c|}
\hline & $\begin{array}{l}\text { PFS Univariate Model } \\
\text { HR [ } 95 \% \text { CI], value }\end{array}$ & $\begin{array}{l}\text { PFS Multivariate model } \\
\text { HR [95\% CI], p value }\end{array}$ & $\begin{array}{l}\text { OS Univariate Model } \\
\text { HR [95\% CI], p value }\end{array}$ & $\begin{array}{l}\text { OS Multivariate Model } \\
\text { HR [95\% CI], p value }\end{array}$ \\
\hline Age $\leq$ or $>70 y$ & 1.19 [0.85-1.66], p 0.295 & & 1.24 [0.89-1.74], p 0.192 & \\
\hline Sex (Female vs Male) & 1.16 [0.83-1.63], p 0.375 & & $1.31[0.93-1.83), \mathrm{p} 0.116$ & 1.53 [1.07-2.16], p 0.017 \\
\hline ECOG PS at Nivo start & $1.14[0.64-2.02], \mathrm{p} 0.644$ & & $1.43[0.80-2.55]$, p 0.217 & \\
\hline Smoking (never vs smoker) & $1.48[0.85-2.06], \mathrm{p} 0.164$ & & $1.73[0.99-3.02], \mathrm{p} 0.054$ & \\
\hline Histology (Non-Sq vs Sq) & $1.26[0.88-1.79], \mathrm{p} 0.192$ & & 1.39 [0.98-1.99], p 0.063 & \\
\hline Brain mets at diagnosis ( $\mathrm{y}$ vs $\mathrm{n}$ ) & $1.12[0.72-1.75], \mathrm{p} 0.602$ & & 1.08 [0.69-1.69], p 0.723 & \\
\hline Bone mets at diagnosis ( $\mathrm{y}$ vs $\mathrm{n}$ ) & $1.43[1.01-2.02], \mathrm{p} 0.038$ & 1.33 [0.95-1.88], p 0.095 & 1.41 (1-1.99), p 0.048 & $1.31[0.92-1.86], \mathrm{p} 0.130$ \\
\hline Liver mets at diagnosis $(\mathrm{y} \vee \mathrm{n})$ & 1.15 [0.74-1.79], p 0.512 & & $1.02(0.66-1.59), \mathrm{p} 0.989$ & \\
\hline EGFR (positive vs negative) & $0.95[0.41-2.15], \mathrm{p} 0.903$ & & $0.79[0.35-1.80], \mathrm{p} 0.588$ & \\
\hline K-RAS (positive vs negative) & 1.11 [0.77-1.60], p 0.547 & & 1.16 [0.81-1.67], p 0.400 & \\
\hline PD-L1 $(\geq 1$ vs $<1)$ & $1.16[0.84-1.60], \mathrm{p} 0.340$ & & 1.13 [0.82-1.55], p 0.439 & \\
\hline NLR baseline $(\geq 5$ vs $<5)$ & $2.97[2.10-4.21], \mathrm{p}<0.00001$ & $2.30[1.55-3.40], \mathrm{p}<0.0001$ & $3.04[2.16-4.26], \mathrm{p}<0.00001$ & $2.30[1.55-3.39], \mathrm{p}<0.0001$ \\
\hline NLR on-treatment $(\geq 5$ vs $<5)$ & $2.3[1.6-3.2], \mathrm{p}<0.00001$ & 1.59 [1.09-2.33], p 0.015 & $2.3[1.8-3.6], \mathrm{p}<0.00001$ & 1.88 [1.28-2.77], p 0.001 \\
\hline Cohorts: 1 (ref) & & & & \\
\hline Cohort 2 (PD-L1-/high LNR) & $2.8[1.76-4.52], \mathrm{p}<0.00001$ & & $3.02[1.89-4.80], \mathrm{p}<0.00001$ & \\
\hline Cohort 3 (PD-L1+/low LNR) & 1.10 [0.71-1.72], p 0.645 & & 1.11 [0.71-1.73], p 0.627 & \\
\hline Cohort 4 (PD-L1+/high LNR) & $3.46[2.18-5.51], \mathrm{p}<0.00001$ & & $3.33[2.14-5.38], \mathrm{p}<0.00001$ & \\
\hline
\end{tabular}

Table 4. Association between HPD status and clinico-pathologic variables for Nivolumab and Platinum-doublet treated Patients with NSCLC. NSq: non squamous non-small cell lung cancer; Sq: squamous cell non-small cell lung cancer; NLR: Neutrophil to Lymphocyte ratio; PD-L1: Programmed Death Ligand 1; On-tx: on therapy; Mets: metastases.

\begin{tabular}{|c|c|c|c|c|c|c|c|c|}
\hline \multicolumn{9}{|l|}{ Hyperprogression } \\
\hline & \multirow{2}{*}{ Age $>65$} & \multirow{2}{*}{$\begin{array}{l}\text { Gender } \\
\left(O^{\lambda} \mathbf{v s} \text { ㅇ }\right)\end{array}$} & \multirow{2}{*}{$\begin{array}{l}\text { Smoking } \\
\text { (y vs n) }\end{array}$} & \multirow{2}{*}{ NSq vs SqHistology } & \multirow{2}{*}{ KRAS mut } & \multirow{2}{*}{ PD-L1+ } & \multirow{2}{*}{ High NLR pre-Tx } & \multirow{2}{*}{$\begin{array}{l}\text { High NLR } \\
\text { on-Tx }\end{array}$} \\
\hline & & & & & & & & \\
\hline \multicolumn{9}{|l|}{ n (\%) } \\
\hline $\begin{array}{l}\text { Nivo } \\
\text { any line }\end{array}$ & $17(35)$ & $32(35)$ & $33 / 36$ & $47(48)$ & $17(45)$ & $33(52)$ & $30(45)$ & $33(43)$ \\
\hline $\mathrm{p}$ & 0.311 & 0.086 & 0.175 & 0.006 & 0.526 & 0.014 & 0.254 & 0.519 \\
\hline $1^{\text {st }}$ line platinum doublet & $8(16)$ & $27(26)$ & $28(26)$ & $24(21)$ & $7(17)$ & $15(20)$ & $13(20)$ & $19(23)$ \\
\hline $\mathrm{p}$ & 0.177 & 0.092 & 0.183 & 0.592 & 0.363 & 0.536 & 0.586 & 0.685 \\
\hline
\end{tabular}

Table 4. Continued.

\begin{tabular}{|c|c|c|c|c|c|c|c|c|c|c|c|}
\hline \multicolumn{12}{|c|}{ Hyperprogression } \\
\hline & On-tx NLR & NLR & On-tx NLR & Cohort1 & Cohort 2 & Cohort 3 & Cohort 4 & Liver & Bone & Brain & Nodes \\
\hline & $\uparrow \geq \mathbf{2 5 \%}$ & no change & $\downarrow \geq \mathbf{2 5 \%}$ & Conotiti & (High NLR) & Conitit & (High NLR) & mets & mets & mets & mets \\
\hline \multicolumn{12}{|l|}{ n (\%) } \\
\hline \multirow{4}{*}{$\begin{array}{l}\text { Nivo } \\
\text { any line } \\
\mathrm{p} \\
1^{\text {st }} \text { line platinum } \\
\text { doublet } \\
\mathrm{p}\end{array}$} & $29(47)$ & $17(34)$ & $11(38)$ & $11(19)$ & $16(28)$ & $13(23)$ & $17(30)$ & $22(73)$ & $35(74)$ & $24(67)$ & $9(75)$ \\
\hline & 0.373 & & & 0.062 & & & & 0.001 & 0.001 & 0.001 & 0.02 \\
\hline & $17(27)$ & $15(23)$ & $3(10)$ & $12(34)$ & $8(23)$ & $10(29)$ & $5(14)$ & $7(27)$ & $9(23)$ & $6(18)$ & $5(45)$ \\
\hline & 0.201 & & & 0.8 & & & & 0.812 & 0.984 & 0.771 & 0.155 \\
\hline
\end{tabular}




\section{Discussion}

In this retrospective study we explored the role of PD-L1, NLR and their combination in predicting response to nivolumab and its influence on hyperprogression. Several studies explored the negative prognostic value of high NLR [31-44], but only few investigated NLR influence on outcome to immunotherapy in NSCLC. To our knowledge, this is the first report that has explored NLR in combination with PD-L1 expression.

Given the poor reliability of PD-L1 and the absence of clear selection criteria for second-line therapy we may run the risk of giving patients an ineffective treatment depriving them of further therapeutic chances. Merging PD-L1 with another predictor, such as NLR, may increase the chance of identifying the group of patients benefitting less from nivolumab. Although we cannot identify a unique cohort with lower response to immunotherapy, our analysis shows that all the high NLR groups (cohorts 2 and 4) derive less benefit from nivolumab.

In terms of response, NLR showed a greater weight in influencing outcome than PD-L1. Patients with low baseline and on-treatment NLR value showed a 3-fold higher ORR than subjects with high NLR, both as single parameter or in combination with PD-L1 status. Both the univariate and multivariate analyses confirmed that high NLR was an independent predictive factor of shorter PFS and OS, irrespective of the timing of blood sampling. No major clinical or pathological features seemed to influence outcome, except for sex. This aspect may be correlated to the high smoke exposure of females included in our study (median 45 packs/year in females and 35 in males). Also male were older than females (male median age 66.6 versus female 61.9), representing a more vulnerable population at higher risk of early treatment discontinuation $[45,46]$.

Previous retrospective reports on NLR change during immunotherapy [47-51] agree that its rapid increase is associated with worse outcome, while an early decline correlates with longer survival.

Differently from previous report by Li M. et al [49], not only patients with minimal NLR excursion during treatment but also those with a large decline from the baseline level reached the longest OS. Since NLR dynamic was mainly due to the excursion in neutrophils rather than the lymphocyte count, we may speculate that survival advantage in those with a deep NLR level decrement was primarily driven by the reduction of tumor-associated neutrophils and myeloid derived suppressor cells that are well known to have an immunosuppressive role [29]. Our findings are consistent with a previous report in metastatic renal cell carcinoma in which an early decline ( $\geq 25 \%$ ) of NLR at 6-weeks was associated with an improved PFS and OS, whereas a relative increase by $\geq 25 \%$ was associated with poor outcomes, regardless of baseline levels [50]. Our analysis showed that the NRL excursion may be informative at 4 weeks. Since restaging in clinical practice usually occurs after a minimum of two months of treatment, a rapid NLR increment after one month of immunotherapy may suggest we are in presence of a poorly sensitive disease and lead clinicians to choose a closer radiological monitoring. This strategy could help avoiding to loose that proportion of patients defined as early progressors to immunotherapy [52]. Moreover, stabilization or reduction of NLR value may support the clinician's choice to continue treatment even in presence of a high disease burden in patients with maintenance of a stable performance status.

To date, no standardized criteria or homogeneous predictive factors are available to define susceptibility to HPD during immunotherapy. Many clinicians believe that this phenomenon is not only a prerogative of checkpoint inhibitors but it may occur also during chemotherapy linked more to the fast progressing habit of the disease than to a direct immunotherapy effect. For this reason, we investigated the rate of HPD under nivolumab in any line compared to HPD seen under chemotherapy in the same group of patients. The majority of patients received a platinum doublet as upfront therapy (97\%). HPD was more common with the PD-1 inhibitor compared to mono-chemotherapy $[14,15]$. Notably, this is the first retrospective study analyzing the incidence of HPD between immunotherapy and a platinum doublet. Although there's not a significant correlation between cohorts and HPD during immunotherapy, those with high baseline NLR show a trend to progress more rapidly compared to the low NLR cohorts. We also observed a strong association with PD-L1 positivity and adenocarcinoma histology, not surprising seen the pro-tumorigenic role of PD-L1 overexpression [53]. A recent large retrospective analysis by Ferrara et al. has not found a significant correlation between NLR $>3$ or PD-L1 status and hyperprogression [15], but the combination of these two parameters and the neutrophils excursion have never been explored. This new pattern of progression seems more likely to be dynamic and multifactorial. Furthermore, in addition to agreeing with previous observations of a significant association between HPD and disease burden [15], we could add that this phenomenon is more dependent on disease quantity rather than the site of metastasis in itself. Conversely, the lack of predictive factors potentially linked to HPD in the same patients population during first line platinum chemotherapy may corroborate the hypothesis that this phenomenon is mainly an immunotherapy prerogative while it would seem a purely random event during chemotherapy.

Although the strength of these associations is limited by sample size, the results of our study highlight the potential of identifying patients who derive less benefit from immunotherapy using a simple and inexpensive tool.

This analysis presents several limitations such as the retrospective design of the study and the limited sample size. To correctly discern the differences between immunotherapy and chemotherapy-induced HPD we should compare those patients who receive an upfront monotherapy with checkpoint inhibitors versus those who are treated exclusively with a platinum-doublet. However, at the time of analysis only few 
patients were treated with a first line immunotherapy as per regulatory rules and, to date, this comparison still remains challenging as the combo chemo-immunotherapy is the standard first line approach for the majority of patients.

\section{Conclusions}

In conclusion, our study showed that NLR value, both at baseline and during treatment, independently correlates with ORR, PFS and OS in advanced NSCLC treated with nivolumab. In our opinion, the most important finding is that immunotherapy cannot revert the negative prognostic influence of high NLR in second or further line of treatment on NSCLC. A high excursion during immunotherapy may identify a cohort of patients with a low likelihood of response to immunotherapy. Importantly, this may help clinicians to identify early patients with low chances to respond or at higher risk of hyper-progression, who may benefit from a closer monitoring or alternative therapies. Considering this is a retrospective analysis, further studies are warranted in order to confirm prospectively these finding.

\section{Acknowledgements}

The authors are grateful to all participating patients and their families. This research did not receive any specific grant from funding agencies in the public, commercial, or not-for-profit sectors.

\section{References}

[1] Reck, M., Rodriguez-Abreu, D., Robinson, AG., Hui, R., Csoszi, T., Fulop, A., Gottfried, M., Peled, N., Tafreshi, A., Cuffe, S., O’Brien, M., Rao, M., Hotta, K., Leiby, MA., Lubiniecki, GM., Shentu, Y., Rangwala, R., Brahmer, JR. (2016). Pembrolizumab versus chemotherapy for PD-L1-positive non-small-cell lung cancer. The New England journal of medicine. 375: 1823-33. https://doi.org/10.1056/nejmoa1606774.

[2] Mok, T. S. K.., Wu, Y. L.,. Kudaba, I., Kowalski, D. M., Cho, C. B., Turna, HZ., Castro J. R, G., Srimuninnimit, V., Laktionov KK., Bondarenko, I., Kubota, K., Lubiniecki G. M., Zhang, J., Jusk, D., Lopes, G. (2019). Pembrolizumab versus chemotherapy for previously untreated, PD-L1-expressing, locally advanced or metastatic non-small-cell lung cancer (KEYNOTE-042): a randomized, open-label, controlled, phase 3 trial. Lancet. 393 (10183): 1819-30. https://doi.org/10.1016/S0140-6736(18)32409.

[3] Carbone, D. P., Reck, M., Paz-Ares, L., Creelan, B., Horn, L., Steins, M., Felip, E., van den Heuvel, M. M., Ciuleanu, T. E., Badin, F., Ready, N., Hiltermann, T., Nair, S., Juergens, R., Peters, S., Minenza, E., Wrangle, J. M., Rodriguez-Abreu, D., Borghaei, H., Blumenschein, G. R., Villaruz, L. C., Havel, L., Krejci, J, Corral, J. J., Chang, H., Geese W. J., Bhagavatheeswaran, P., Chen, A. C., Socinski, M. A. CheckMate 026 Investigators (2017). First-Line Nivolumab in Stage IV or Recurrent Non-Small-Cell Lung Cancer. The New England journal of medicine. 376 (25), 2415-2426. https://doi.org/ 10.1056/NEJMoa1613493.
[4] Gandhi, L., Rodrigues-Abreu, D., Gadgeel, S., Esteban, E., Felip, E., De Angelis, F., Domine, M., Clingan, P., Hochmair, M. J., Powell, S. F., Cheng, S. Y. S., Bischoff, H. G., Peled, N., Grossi, F., Jennens, R. R., Reck, M., Hui, R., Garon, E. B., Boyer, M., Rubio-Viqueira, B., Novello, S., Kurata, T., Gray, J. E., Vida, J., Wei, Z., Yang, J., Raftopoulos, H., Pietanza, M. C., Garassino, M. C.; KEYNOTE-189 Investigators. (2018). Pembrolizumab plus Chemotherapy in Metastatic Non-Small-Cell Lung Cancer. New England Journal of Medicine. 378 (22): 2078-2092. https://doi.org/10.1056/NEJMoa1801005.

[5] Paz-Ares, L., Luft, A., Vicente, D., Tafreshi, A., Gumus, M., Mazieres, J., Hermes, B., Senler, F. C., Csoszi, T., Fulop, A., Rodriguez-Cid, Wilson, J., Sugawara, S., Kato, T., Lee, K. H., Cheng, Y., Novello, S., Halmos, B., Li, X., Lubiniecki, G. M., Biperdi, B., Kowalski, D. M., for the KEYNOTE-407 Investigators (2018). Pembrolizumab plus Chemotherapy for Squamous Non-Small-Cell Lung Cancer. The New England Journal of Medicine, 379 (21), 2040-2051. https://doi.org/10.1056/NEJMoa1810865.

[6] Borghaei, H., Paz-Ares, L., Horn, L., Spigel, D. R., Steins, M., Ready, N. E., Chow, L. Q., Vokes, E. E., Felip, E., Holgado, E., Barlesi, F., Kohlhäufl, M., Arrieta, O., Burgio, M. A., Fayette, J., Lena, H., Poddubskaya, E., Gerber, D. E., Gettinger, S. N., Rudin, C. M., Rizvi, N., Crinò, L., Blumenschein, G. R., Antonia, S. J., Dorange, C., Harbison, C. T., Finckenstein, F. G., and Brahmer, G. R. (2015). Nivolumab versus docetaxel in advanced nonsquamous non-small-cell lung cancer. New England Journal of Medicine; 373: 1627-1639. https://doi.org/10.1056/NEJMoa1507643.

[7] Brahmer, J., Reckamp, K. L., Baas, P., Crinò, L, Eberhardt, W. E. E., Poddubskaya, E., Antonia, S., Pluzanski, A., Vokes, E. E., Holgado, E., Waterhouse, D., Ready, N., Gainor, J., Frontera, O. A., Havel, L., Steins, M., Garassino, M. C., Aerts, J. C., Domine, M., Paz-Ares, L., Reck, M., Baudelet, C., Harbison, C T., Lestini, B., and Spigel, D. R. (2015). Nivolumab versus docetaxel in advanced squamous-cell non-small-cell lung cancer. New England Journal of Medicine. 373: 123-135. https://doi.org/10.1056/NEJMoa1504627.

[8] Herbst, R. S., Baas, P., Kim, D. W., Felip, E., Pérez-Gracia, J. L., Han, J. L., Molina, J., Kim, J. H., Dubos Arvis, C., Ahn, M. J., Majem, M., Fidler, M. J., M. J., de Castro, G., Jr, Garrido, M., Lubiniecki, G. M., Shentu, Y., Im, E., Dolled-Filhart, M., \&Garon, E. B. (2016). Pembrolizumab versus docetaxel for previously treated, PD-L1-positive, advanced non-small-cell lung cancer (KEYNOTE-010): a randomised controlled trial. Lancet. $\quad 387 \quad$ (10027), $1540-1550$. https://doi.org/10.1016/S0140-6736(15)01281-7.

[9] Rittmeyer, A., Barlesi, F., Waterkamp, D., Park, K., Ciardiello, F., von Pawel, J., Gadgeel, S. M., Hida, T., Kowalski, D. M., Dols, M. C., Cortinovis, D. L., Leach, J., Polikoff, J., Barrios, C., Kabbinavar, F., Frontera, O. A., De Marinis, F., Turna, H., Lee, J. S., Ballinger, M., Kowanetz, M., He, P., Chen, D. S. Sandler, A., Gandara, D. R., OAK Study Group. OAK Study Group. (2017). Atezolizumab versus docetaxel in patients with previously treated non-small-cell lung cancer (OAK): a phase 3, open-label, multicentrerandomised controlled trial. Lancet. 389: 255-265. https://doi.org/10.1016/S0140-6736(16)32517-X.

[10] GiajLevra, M., Cotté, F. E., Corre, R., Calvet, C., Gaudin, A. F., Penrod, J. R., Grumberg, V., Jouaneton, B., Jolivel, R., Assié, J. B., Chouaïd, C. (2020). Immunotherapy rechallenge after nivolumab treatment in advanced non-small cell lung cancer in the real-world setting: A national data base analysis. Lung cancer. 140, 99-106. https://doi.org/10.1016/j.lungcan.2019.12.017. 
[11] Gobbini E, Toffart A, Perol M, Assie JB, Duruisseaux M, Coupez D et al. Immune checkpoint inhibitors rechallenge efficacy in Non-Small-Cell Lung Cancer Patients. Clin Lung Cancer. 2020; 21 (5): e497-e510. doi: 10.1016/j.cllc.2020.04.013.

[12] Dubos, C., Westeel, W., Delaunay, M., Guisier, F., Veillon, R., Gounant, V., Giroux Leprieur, E., Vanel, F. R., Chaabane, N., Dansin, E., Babey, H., Decroisette, C., Barlesi, F., Daniel, C., Fournel, P., Mezquita, L., Oulkhouir, Y., Canellans, A., Duchemann, B., Molinier, O., Alcazer, V., Moro-Sibilet, D., Levra, M. G. (2020). Immune Checkpoint Inhibitors Rechallenge Efficacy in Non-Small-Cell Lung Cancer Patients. Clinical lung cancer, 21 (5), e497-e510. https://doi.org/10.1016/j.cllc.2020.04.013

[13] Hellmann, M. D., Ciuleanu, T. E., Pluzanski, A., Lee, J. S., Otterson, G. A., Audigier-Valette, C., Minenza, E., Linardou, H., Burgers, S., Salman, P., Borghaei, H., Ramalingam, S. S., Brahmer, J., Reck, M., O'Byrne, K. J., Geese, W. J., Green, G., Chang, H., Szustakowski, J., Bhagavatheeswaran, P., Healey, D., Fu, Y., Nathan, F., Paz-Ares, L. (2018). Nivolumab plus Ipilimumab in Lung Cancer with a High Tumor Mutational Burden. The New England journal of medicine, 378 (22), 2093-2104. https://doi.org/10.1056/NEJMoa1801946.

[14] Ready, N., Hellmann, M. D., Awad, M. M., Otterson, G. A., Gutierrez, M., Gainor, J. F., Borghaei, H., Jolivet, J., Horn, L., Mates, M., Brahmer, J., Rabinowitz, I., Reddy, P. S., Chesney, J., Orcutt, J., Spigel, D. R., Reck, M., O'Byrne, K. J., Paz-Ares, L., Hu, W., Zerba, K., Li, X., Lestini, B., Geese, W. J., Szustakowski, J. D., Chang, H., Ramalingam, S. S. (2019). First-Line Nivolumab Plus Ipilimumab in Advanced Non-Small-Cell Lung Cancer (CheckMate 568): Outcomes by Programmed Death Ligand 1 and Tumor Mutational Burden as Biomarkers. Journal of clinical oncology. 37 (12), 992-1000. https://dx.doi.org/10.1200\%2FJCO.18.01042.

[15] Champiat, S., Dercle, L., Ammari, S., Massard, C., Hollebecque, A., Postel-Vinay, S., Chaput, N., Eggermont, A., Marabelle, A., Soria, J-C., Ferté, C. (2017). Hyperprogressive disease is a new pattern of progression in cancer patients treated by anti-PD-1/ PD-L1. Clin Cancer Res 2017; 23: 1920 8. https://doi.org/10.1158/1078-0432.ccr-16-1741.

[16] Ferrara, R., Mezquita, L., Texier, M., Lahmar, J., Audigier-Valette, C., Tessonnier, L., Mazieres, J., Zalcman, G., Brosseau, S., Le Moulec, S., Leroy, L., Duchemann, B., Lefebvre, C., Veillon, R., Westeel, V., Koscielny, S., Champiat, S., Ferté, C., Planchard, D., Remon, J., Boucher, M. E., Gazzah, A., Adam, J., Bria, E., Tortora, G., Soria, J. C., Besse, B., Caramella, C. (2018). Hyperprogressive Disease in Patients With Advanced Non-Small Cell Lung Cancer Treated With PD-1/PD-L1 Inhibitors or With Single-Agent Chemotherapy. JAMA oncology, 4 (11), 1543-1552. https://doi.org/10.1001/jamaoncol.2018.3676

[17] Dahan, R., Sega, E., Engelhardt, J., Selby, M., Korman, A. J., Ravetch. J. V. (2015) FcgammaRs modulate the anti-tumor activity of antibodies targeting the PD-1/PD-L1 axis. Cancer Cell. 28: 285-295. https://doi.org/10.1016/j.ccell.2015.08.004.

[18] Lo Russo, G., Moro, M., Sommariva, M., Cancila, V., Boeri, M., Centonze, G. Ferro, S., Ganzinelli, M., Gasparini, P., Huber, V., Milione, M., Porcu, L., Proto, C., Pruneri, G., Signorelli, D., Sangaletti, S., Sfondrini, L., Storti, C., Tassi, E., Bardelli, A., Marsoni, S., Torri, V., Tripodo, C., Colombo, M. P., Anichini, A., Rivoltini, L., Balsari, A., Sozzi, G., Garassino, M. C. (2019). Antibody-Fc/FcR Interaction on Macrophages as a Mechanism for Hyperprogressive Disease in Non-small Cell
Lung Cancer Subsequent to PD-1/PD-L1 Blockade. Clinical $\begin{array}{llll}\text { cancer } & \text { research. } & 25 & \text { (3), }\end{array}$ https://doi.org/10.1158/1078-0432.ccr-18-1390.

[19] Xiong, D., Wang, Y., Singavi, A. K., Mackinnon, A. C., George, B., You, M. (2018). Immunogenomic Landscape Contributes to Hyperprogressive Disease after Anti-PD-1 Immunotherapy for Cancer. $\quad$ IScience. $\quad 9$ : 258-77. https://doi.org/10.1016/j.isci.2018.10.021.

[20] CedresS, Torrejon D, Martınez A, Martiniz P, Navarro A, Zamora E, Mulet-Margalef, N., Felip, e. (2012). Neutrophil to lymphocyte ratio (NLR) as an indicator of poor prognosis in stage IV non-small cell lung cancer. Clinical \& translational oncology. 14: 864-869. https://doi.org/10.1007/s12094-012-0872-5.

[21] Bagley, S. J., Kothari, S., Aggarwal, C., Baulm, J. M., Alley, E. W., Evans, T. L. Stonehouse-Lee, S., Sherry, V. E., Gilbert, E., Eaby-Sandy, B., Mutale, F., DiLullo, G., Cohen, R. B., Vachani, A., Langer, C. J. (2017). Pretreatment neutrophil-to-lymphocyte ratio as a marker of outcomes in nivolumab-treated patients with advanced non-small-cell lung cancer. Lung cancer. 106, 1-7. https://doi.org/10.1016/j.lungcan.2017.01.013.

[22] Capone, M., Giannarelli, D., Mallardo, D., Madonna, G., Festino, L., Grimaldi, A. M., Vanella, V., Simeone, E., Paone, M., Palmieri, G., Cavalcanti, E., Caracò, C., Ascierto, P. A. (2018). Baseline neutrophil-to-lymphocyte ratio (NLR) and derived NLR could predict overall survival in patients with advanced melanoma treated with nivolumab. Journal for immunotherapy of cancer. 6 (1), 74. https://doi.org/10.1186/s40425-018-0383-1.

[23] Lalani, A. A., Xie, W., Martini, D. J., Steinharter, J. A., Norton, C. K., Krajewski, K. M., Duquette, A., Bossé, D., Bellmunt, J., Van Allen, E. M., McGregor, B. A., Creighton, C. J., Harshman, L. C., Choueiri, T. K. (2018). Change in Neutrophil-to-lymphocyte ratio (NLR) in response to immune checkpoint blockade for metastatic renal cell carcinoma. Journal for immunotherapy of cancer, 6 (1), 5 . https://doi.org/10.1186/s40425-018-0315-0.

[24] Park, W., Kwon, D., Saravia, D., Desai, A., Vargas, F., EI Dinali, M. Warsch, J., Elias, R., Chae, Y. K. Kim, D. W., Warsch, S., Ishkanian, A., Ikpeazu, C., Mudad, R., Lopes, G., Jahanzeb, M. (2018). Developing a Predictive Model for Clinical Outcomes of Advanced Non-Small Cell Lung Cancer Patients Treated WithNivolumab. Clinical lung cancer, 19 (3), 280-288. https://doi.org/10.1016/j.cllc.2017.12.007.

[25] Cao, D., Xu, H., Xu, X., Tao, G., Ge. W. (2018). A reliable and feasible way to predict the benefits of Nivolumab in patients with non-small cell lung cancer: a pooled analysis of 14 retrospective studies. Oncoimmunology. 7 (11): e1507262. https://dx.doi.org/10.1080\%2F2162402X.2018.1507262.

[26] Sacdalan, D. B., Lucero, J. A., Sacdalan, D. L. (2018). Prognostic utility of baseline neutrophil-to-lymphocyte ratio in patients receiving immune checkpoint inhibitors: A review and meta-analysis. OncoTargets and Therapy. 11: 955-965. https://doi.org/10.2147/ott.s153290.

[27] Jiang T, Qiao M, Zhao C.. Li, X., Gao, G., Su, C., Ren, S., Zhou, C. (2018). Pretreatment neutrophil-to-lymphocyte ratio is associated with outcome of advanced-stage cancer patients treated with immunotherapy: a meta-analysis. Cancer Immunology, Immunotherapy. 67: 713-727. https://doi.org/10.1007/s00262-018-2126-z. 
[28] Khunger, M., Patil, P. D., Khunger, A., Li, M., Hu, B., Rakshit, S., Basu, A., Pennel, N., Stevenson, J. P., Elson, P., Panchabhai, T. S., Velcheti, V. (2018). Post-treatment changes in hematological parameters predict response to nivolumab monotherapy in non-small cell lung cancer patients. PLoS One. 13: e0197743. https://doi.org/10.1371/journal.pone.0197743.

[29] Dusselier, M., Deluche, E., Delacourt, N., Ballouhey, J., Egenod, T., Melloni, B., Vergnenègre, C., Veillon, R., Vergnenègre, A. (2019). Neutrophil-to-lymphocyte ratio evolution is an independent predictor of early progression of second-line nivolumab-treated patients with advanced non-small-cell lung cancers. PloS one, 14 (7), e0219060. https://doi.org/10.1371/journal.pone.0219060.

[30] Eisenhauer, E. A., Therasse, P., Bogaerts, J., Schwartz, L. H., Sargent, D., Ford, R., Dancey, J., Arbuck, S., Gwyther, S., Mooney M., Rubinstein, L., Shankar, L., Dodd, L., Kaplan, R., Lacombe, D., \&Verweij, J. (2009). New response evaluation criteria in solid tumours: revised RECIST guideline (version 1.1). European journal of cancer. 45 (2), 228-247. https://doi.org/10.1016/j.ejca.2008.10.026.

[31] Emels LA and Middleton G. (2015) The Interplay of Immunotherapy and Chemotherapy: Harnessing Potential Synergies. Cancer immunology research. 3 (59): 436-443. https://dx.doi.org/10.1158\%2F2326-6066.CIR-15-0064.

[32] Yin, Y., Wang, J., Wang, X., Gu, L., Pei, H., Kuai, S., Zhang, Y., Shang, Z. (2015). Prognostic value of the neutrophil to lymphocyte ratio in lung cancer: A meta-analysis. Clinics (Sao Paulo, Brazil), $70 \quad$ (7), 524-530. https://dx.doi.org/10.6061\%2Fclinics\%2F2015(07)10.

[33] Diem, S., Schmid, S., Krapf, M. Flatz, L., Born, D., Jochum, W., Templeton, A. J., Fruh, M. (2017). Neutrophil-to-Lymphocyte ratio (NLR) and Platelet-to-Lymphocyte ratio (PLR) as prognostic markers in patients with non-small cell lung cancer (NSCLC) treated with nivolumab. Lung Cancer. 111: 176-181. https://doi.org/10.1016/j.lungcan.2017.07.024.

[34] Cannon, N. A., Meyer, J., Iyengar, P., Ahn, C., Westover, K. D., Choy, H., Timmerman, R. (2015). Neutrophil-lymphocyte and platelet-lymphocyte ratios as prognostic factors after stereotactic radiation therapy for early-stage non-small-cell lung cancer. Journal of Thoracic Oncology. 10 (2): 280-5. https://doi.org/10.1097/jto.0000000000000399.

[35] Kang, M. H., Go, S. I., Song, H. N., Kang, M. H., Go, S. I., Song, H. N., Lee, A., Kim, S. H., Kang, J. H., Jeong, B. K., Kang, K. M., Ling, H., Lee, G. W. (2014). The prognostic impact of the neutrophil-to-lymphocyte ratio in patients with small-cell lung cancer, British Journal of Cancer. 111 (3): 452-60. https://doi.org/10.1038/bjc.2014.317.

[36] Wu, G., Yao, Y., Bai, C., Zeng, J., Shi, D., Gu, X., Shi, X., \& Song, Y. (2015). Combination of platelet to lymphocyte ratio and neutrophil to lymphocyte ratio is a useful prognostic factor in advanced non-small cell lung cancer patients. Thoracic cancer, $\quad 6 \quad$ (3), 275-287. https://dx.doi.org/10.1111\%2F1759-7714.12178.

[37] Hong, X., Cui, B., Wang, M., Yang, Z., Wang, L., Xu, Q. (2015) Systemic Immune-inflammation Index, Based on Platelet Counts and Neutrophil-Lymphocyte Ratio, Is Useful for Predicting Prognosis in Small Cell Lung Cancer. J Exp Med. 236 (4): 297-304. https://doi.org/10.1620/tjem.236.297.
[38] Deng, M., Ma, X., Liang, X., Zhu, C., Wang, M. (2017) Are pretreatment neutrophil-lymphocyte ratio and platelet-lymphocyte ratio useful in predicting the outcomes of patients with small-cell lung cancer? Oncotarget. 8 (23): 37200-37207. https://doi.org/10.18632/oncotarget.16553.

[39] Shao, N., Cai Q. (2015). High pretreatment neutrophil-lymphocyte ratio predicts recurrence and poor prognosis for combined small cell lung cancer. Clinical and Translational Oncology. 17: 772-778. https://doi.org/10.1007/s12094-015-1289-8.

[40] Zhang, H., Xia, H., Zhang, L., Bin, Z., Yue, D., Wang, C. (2015). Clinical significance of preoperative neutrophil-lymphocyte vs platelet-lymphocyte ratio in primary operable patients with non-small cell lung cancer. American Journal of Surgery. 210: 526-35. https://doi.org/10.1016/j.amjsurg.2015.03.022.

[41] Shimizu, K., Okita, R., Saisho, S., Maeda, A., Nojima, Y., Nakata, M. (2015). Preoperative neutrophil/lymphocyte ratio and prognostic nutritional index predict survival in patients with non-small cell lung cancer. World journal of surgical oncology, 13 , https://doi.org/10.1186/s12957-015-0710-7.

[42] Takahashi, Y., Horio, H., Hato, T., Harada, M., Matsutani, N., Morita, S., Kawamura, M. (2015). PrognosticSignificance of PreoperativeNeutrophil-LymphocyteRatios in Patients with Stage I Non-small Cell LungCancerAfter Complete Resection. Annals of SurgicalOncology. 22: 1324-31. https://doi.org/10.1245/s10434-015-4735-5.

[43] Zhang, L., Zhu, K., Shi, B., Yin, Y., Zhu, J., Yue, D., Zhang, B., Wang, C.(2015). Prognosticsignificance of combination of preoperativeplateletcount and NeutrophilLymphocyte ratio (COP-NLR) in patients with non-small celllungcancer: Based on alarge cohort study. PLoSOne 2015; 10: e0126496. https://doi.org/10.1371/journal.pone.0126496.

[44] Yu Y, Qian L and Cui J. (2017). Value of neutrophil-to-lymphocyte ratio for predicting lung cancer prognosis: A meta-analysis of 7,219 patients. Molecular and $\begin{array}{llll}\text { Clinical Oncology. } & 7 & \text { (3): } & 498-506 .\end{array}$ https://doi.org/10.3892/mco.2017.1342.

[45] Nakao, M., Muramatsu, H., Kagawa, Y., Nakao, M., Muramatsu, H., Kagawa, Y., Suzuki, Y., Sakai, Y., Kurokawa, R., Fujita, K., Sato, H. (2017). Immunological Status May Predict Response to Nivolumab in Non-small Cell Lung Cancer without Driver Mutations. Anticancer research. $\quad 37 \quad$ (7): 3781-3786. https://doi.org/10.21873/anticanres.11753.

[46] Wang, S., Cowley, L. A., \& Liu, X. S. (2019). Sex Differences in Cancer Immunotherapy Efficacy, Biomarkers, and Therapeutic Strategy. Molecules (Basel, Switzerland), 24 (18), 3214..-https://doi.org/10.3390/molecules24183214.

[47] van Holstein, Y., Kapiteijn, E., Bastiaannet, van den Bos, F., Portielje, J., A. de Glas, N. (2019). Efficacy and Adverse Events of Immunotherapy with Checkpoint Inhibitors in Older Patients with Cancer. Drugs Aging. 36 (10): 927-938. https://doi.org/10.1007/s40266-019-00697-2.

[48] Moschetta, M., Uccello, M., Kasenda, B., Mak, G., McClelland, A., Boussios, S., Forster, M., Arkenau, H. T. (2017) Dynamics of Neutrophils-to-Lymphocyte Ratio Predict Outcomes of PD-1/PD-L1 Blockade. BioMed research. 1506824. https://doi.org/10.1155/2017/1506824. 
[49] Li, M., Spakowicz, D., Burkart, J., Patel, S., Husain, M., He, K., Bertino, E. M., Shields, P. G., Carbone, D. P., Verschraegen, C. F., Presley, C. J., Otterson, G. A., Kendra, K., \& Owen, D. H. (2019). Change in neutrophil to lymphocyte ratio during immunotherapy treatment is a non-linear predictor of patient outcomes in advanced cancers. Journal of cancer research and clinical oncology, $145 \quad$ (10), 2541-2546. https://doi.org/10.1007/s00432-019-02982-4.

[50] Russo, A., Russano, M., Franchina, T., Migliorino, M. R., Aprile, G., Mansueto, G., Berruti, A., Falcone, A., Aieta, M., Gelibter, A., Russo, A., Barni, S., Maio, M., Martelli, O., Pantano, F., Iacono, D., Calvetti, L., Quadrini, S., Roca, E., Vasile, E., Imperatori, M., Occhipinti, M., Galvano, A., Petrelli, F., Calabrò, L, Pasquini, G., Intagliata, S., Ricciardi, G. R. R., Tonini, G., Santini, D., Adamo, V. (2020). Neutrophil-to-Lymphocyte Ratio (NLR), Platelet-to-Lymphocyte Ratio (PLR), and Outcomes with Nivolumab in Pretreated Non-Small Cell Lung Cancer
(NSCLC): A Large Retrospective Multicenter Study. Advances
in therapy,
37
(3), $1145-1155$. https://doi.org/10.1007/s12325-020-01229-w.

[51] Suh, K. J., Kim, S. H., Kim, Y. J. Kim, M., Keam, B., Kim, T. M., Kim, D-W., Heo, D. S., Lee, J. S. (2018). Post-treatment neutrophil-to-lymphocyte ratio at week 6 is prognostic in patients with advanced non-small cell lung cancers treated with anti-PD-1 antibody. Cancer Immunology, Immunotherapy. 67 (3), 459-470. https://doi.org/10.1007/s00262-017-2092-x.

[52] Shaul, M. E., Fridlender, Z. G. (2019) Tumour-associated neutrophils in patients with cancer. Nature Reviews Clinical Oncology. 16, 601-620. https://doi.org/10.1038/s41571-019-0222-4.

[53] Hiren A. Mandaliya, Sang Kim. Mortality within 30 days of immunotherapy (checkpoint inhibitors) in metastatic cancer patients treated at Australian tertiary cancer center. Journal of Clinical Oncology 2019 37: 15 _suppl, 6600-6600. 